\title{
Using the Vocabulary Self-Collection Strategy Plus to Develop University EFL Students' Vocabulary Learning
}

\author{
Manal Mohamed Khodary ${ }^{1}$ \\ ${ }^{1}$ Faculty of Education, Suez Canal University, Ismailia, Egypt \\ Correspondence: Manal Mohamed Khodary, Faculty of Education, Suez Canal University, Ismailia, Egypt. \\ E-mail: manalkhodary@yahoo.com
}

Received: May 3, 2017 Accepted: July 15, 2017 Online Published: July 17, 2017

doi: 10.5539/elt.v10n8p135 URL: http://doi.org/10.5539/elt.v10n8p135

\begin{abstract}
This study was carried out to examine the effectiveness of using the Vocabulary Self-Collection Strategy Plus (VSSPlus) on developing university EFL students' vocabulary learning. It adopted the quasi experimental design which included two groups design. The participants were first level students at Languages and Translation Department, Arar Faculty of Education and Arts, Northern Border University, KSA. They formed two groups: an experimental group $(n=40)$ and a control one $(n=40)$. Both groups were pre-tested by using the pre Vocabulary Achievement Test (VAT) for equivalence in vocabulary prior to the treatment. The researcher taught the experimental group throughout the sessions that based on using the VSSPlus in vocabulary learning and she taught vocabulary to the control group by using the Vocabulary Self-Collection Strategy (VSS). Then, the researcher post tested the two groups by using the post VAT and she used the t-test to calculate the differences between the mean scores of the pre and post VAT. The results revealed that a statistically significant difference was found between the mean scores of the experimental group and the control group on the post VAT in favor of the experimental group. The results also showed that a statistically significant difference was found in the mean scores of the experimental group between the pre and post VAT in favor of the post VAT. Therefore, it was concluded that the experimental group outperformed the control group on the post VAT as a result of receiving training on the VSSPlus. It was also concluded that the experimental group performed better on the post VAT than the pre VAT because the VSSPlus helped them develop vocabulary. Some recommendations and suggestions for further research were provided.
\end{abstract}

Keywords: the vocabulary self-collection strategy plus, university EFL students, vocabulary

\section{Introduction}

\subsection{Background to the Study}

Vocabulary is regarded as an important aspect in language learning. It is also considered as a necessary component for improving competency in all areas of communication among users of a language (Celik \& Toptas, 2010; Hoshino, 2010). It is a unique constituent that connects the four language skills of speaking, listening, reading and writing together. Moreover, it has an essential role in learning a Foreign Language (FL) (Kabiri \& Ghafoori, 2014). The possessing of a good amount and right knowledge of vocabulary achieves a significant role in people's lives and future potentials (Godwin, 2010). Therefore, it is important for learners of a FL to attain a rich amount of comprehensible vocabulary in order to be able to communicate well using the target language (Dolati \& Mikaili, 2011). In fact, vocabulary instruction can be done before reading a particular reading material through teaching its key vocabulary prior to reading the material. It can also be accomplished during reading instruction by teaching what emerges as required throughout reading a selected material and it can also be done after reading a specific material. The Vocabulary Self-Collection Strategy Plus (VSSPlus) is an after reading strategy and a variant of the Vocabulary Self-Collection Strategy (VSS) with the addition of various technological tools to cope with the requirements of learning in our recent digital era and to enable students to achieve deep comprehension of the terms provided in the selected text (Wolsey, Smetana, \& Grisham, 2015).

The researcher taught a Vocabulary Building course to first level students at Languages and Translation Department, Arar Faculty of Education and Arts, Northern Border University (NBU), Kingdom of Saudi Arabia (KSA). She noticed that most of first level students suffered from weaknesses in vocabulary. Moreover, instructors of English as a Foreign Language (EFL) at this department indicated that their students lack 
vocabulary skills. Such lack of students' vocabulary was revealed in their inability to recognize the meaning of vocabulary which they heard and read. Besides, they had spelling mistakes when they wrote vocabulary and they were unable to use new vocabulary to make correct sentences. Thus, most of them were not capable of expressing themselves, ideas and information because they did not have the enough amount of vocabulary needed for good communication.

To make sure of the vocabulary problem among first level students, the reseacher checked their scores which they had got on previous vocabulary exams and she found that they had obtained low scores in these exams. Furthermore, the researcher conducted an interview with 15 first level students about the vocabulary problems they had. They pointed out that they suffered from weaknesses in vocabulary. They indicated that the weaknesses in vocabulary they had were represented in their inability to remember many words which they had previously studied. They mentioned that they were always not motivated to learn new vocabulary. They pointed out that thev felt confused when they tried to give the correct meaning of new vocabulary and were unable to write the correct spelling of words in correct sentences. Moreover, they assured that their vocabulary weaknesses might stem from the unsuitable methods of teaching vocabulary provided to them by their instructors. They indicated that they need training on the use of new strategies in vocabulary learning to help them develop vocabulary. The researcher also reviewed Saudi studies conducted on EFL university students' vocabulary. She found that studies designed by Al-Nuiaidi (2003), Albousaif (2012) and Altalhab (2016) were carried out because Saudi EFL university students had difficulty in vocabulary learning.

\subsection{Statement of the Problem}

It was revealed that first level Languages and Translation Department students had weaknesses in English vocabulary. To solve this problem, the researcher conducted the current study in order to investigate the effectiveness of using the VSSPlus in developing vocabulary learning among first level students.

\subsection{Literature Review}

\subsubsection{Vocabulary Teaching and Learning}

Teaching of a FL has recently focused on the use of the communicative approach which is based on the functions of language (Yule, 2006). Thus, vocabulary teaching has been directed to be applied in meaningful sets that emphasize student-centred classes rather than teacher-centred classes (D. Willis \& J. Willis, 2007). Moreover, vocabulary teaching should comprise of teaching learners particular words as well as training them by using strategies essential for expanding their vocabulary knowledge (Hulstijn, 2001). Technology can be used as an essential part of academic teaching, especially of vocabulary teaching (Clark, 2013). Many previous studies implemented technological devices such as computers, videos and tablets into the teaching of vocabulary and they revealed positive results on developing vocabulary among learners (Dalton \& Grisham, 2011; Perez, Peters, Clarebout, \& Desmet, 2014). Vocabulary learning plays a major role in the academic achievement of EFL learners (Gersten \& Baker, 2000). It is regarded as an activity and a social transaction which could be facilitated by objects and digital tools (Arenseth, 2008). Learners learn the vocabulary which they need for use and which has importance and significance for them (Wolsey et al., 2015). Learning of vocabulary happens as a consequence of frequent exposures to concepts represented by the words being selected, studied and thus their meanings could be comprehended (Eckerth \& Tavakoli, 2012). It can also occur when students read about ideas beyond the selected words, write about them, present and discuss them with peers, think about the deeper inferences of vocabulary in particular contexts and depend on resources to support their thinking (Wolsey, Grisham, \& Smetana, 2014).

\subsubsection{Importance of Vocabulary Development}

Vocabulary development is necessary for learners of a FL because without vocabulary, communication is not possible (Wilkins, 1972; Kilickaya \& Krajka, 2010). To Ghazal (2007) "words are the building blocks of a language" (p. 84). Thus, it is necessary for FL learners to acquire a good amount of vocabulary in order to be able to communicate effectively (Dolati \& Mikaili, 2011). Moreover, the necessity for developing the ability to comprehend vocabulary and achieve accurate use of vocabulary increases in importance because there is a growing demand for achieving advanced literacy skills (Scott \& Ytreberg, 2001). This highlights the need of learners for acquiring knowledge of word meanings, word concepts, and interpretations of vocabulary in order to understand various types of texts (Chen, 2014).

\subsubsection{The VSSPlus}

The VSSPlus is an approach that relies on the elements of the VSS, which was orginated by Haggard in 1982. The VSS is an approach which should be done after reading a selected reading material (Haggard, 1982; 1986). 
It includes the following steps: Selecting words, defining the selected words, finalizing the words list and extending words knowledge (Wulansari, 2016). The purpose of the VSS is to enable the long-term acquisition of vocabulary (Stoddard, 2006). The VSSPlus resembles the VSS to some extent in that it also occurs as a post reading activity but the difference between them lies in that the VSSPlus requires from its users to integrate various applications of technological tools during its practice.

The VSSPlus is always implemented with the purpose of allowing students to make a list of selected words from a post reading material in order to explore and learn the selected words. Besides, it is used to let them expand their prior knowledge of the selected words and to deepen their understanding of them and motivate their growth in word knowledge (Lester \& Elliot, 2002). The VSSPlus is based on giving opportunities to students to select words which are important to know, have several exposure to the selected words, do numerous readings of a text, collaborate together and with their instructor to do oral discussions and presentations, do Internet search, record a podcast and build semantic webs. Through the VSSPlus, students can use higher order thinking skills in combination with technological tools of various types to achieve their deep comprehension of the terms which are related to their study of a reading text. Technology used in the VSSPlus should be applied in a generative way which means that learners use technological tools to satisfy their needs for learning and to fulfill their interest in learning (Grisham \& Smetana, 2011). The role of the instructor during carrying out the VSSPlus is to perform as a facilitator of the process of conducting the strategy represented in facilitating the oral discussion, helping in the selection process of words and distributing students into small teams (Wolsey et al., 2015).

The VSSPlus is still a new strategy which can be used for vocabulary teaching and learning. The only try on the use of the VSSPlus to teach vocabulary was done by Grisham, Wolsey and Smetana (2013) in a form of suggested procedures intended for carrying out the VSSPlus in vocabulary teaching and learning. No previous studies, to the researcher's knowledge, were carried out on investigating the effectiveness of the VSSPlus on improving vocabulary learning among university EFL students in KSA. Therefore, the researcher carried out the current study to reveal if the VSSPlus could develop vocabulary learning among first level students.

\subsection{Hypotheses}

1.4.1 A statistically significant difference $(\mathrm{p}<0.05)$ would be found between the mean scores of the experimental group and the control group on the post VAT in favor of the experimental group.

1.4.2 A statistically significant difference $(\mathrm{p}<0.05)$ would be found in the mean scores of the experimental group between the pre and post VAT in favor of the post VAT.

\subsection{Aim}

The current study aimed at investigating the effectiveness of using the VSSPlus in developing vocabulary learning among first level Languages and Translation Department students.

\subsection{Significance}

The current study might be significant to first level Languages and Translation Department students since it could offer them the overall benefits of blending various technological tools with the VSS to develop their vocabulary learning. It could also be significant to EFL instructors as it might provide them with a new strategy based on benefiting from the usefulness of integrating technological tools with the VSS in vocabulary teaching to help their students develop vocabulary learning.

\subsection{Definition of Terms}

\subsubsection{The VSSPlus}

The researcher stated an operational definition for the VSSPlus as a post reading strategy which is based on using technological tools in studying unknown words selected from a post reading material to activate students' prior knowledge and information of the selected words to generate multiple meanings for them and hence develop vocabulary.

\subsubsection{Vocabulary}

The researcher operationally defined vocabulary as the overall amount of words which a user needs to communicate ideas, give information and express feelings and opinions to others and to understand what others inform in oral and print forms. It involves vocabulary mastery regarding knowledge of a user of word meanings, word concepts, and word interpretations. 


\section{Method}

\subsection{Research Design}

It is a pre, post test quasi experimental study which included two groups: an experimental group and a control one. The researcher used the pre VAT to check whether the experimental group and the control group were equivalent in vocabulary prior to carrying out the treatment and she used the post VAT to post test them by the end of the treatment. Then, the researcher used the t-test to calculate the differences between the mean scores of the pre VAT and the post VAT.

\subsection{Variables}

The independent variable in the current study is the VSSPlus whereas the dependent variable is first level students' vocabulary.

\subsection{Participants}

The participants were first level Languages and Translation Department female students at Arar Faculty of Education and Arts. Their age ranged from 19-21 years. They have been learning EFL for nearly 11 years. They studied Vocabulary Building course in a session of 3 hours once a week as required by their department. They were randomly assigned into classes by their faculty. The researcher randomly selected 2 classes from her list of classes and she randomly assigned one class as the experimental group $(n=40)$ while the other class as the control group $(n=40)$. All of the participants did not have any previous experience with receiving a training on the VSSPlus or with practicing the VSSPlus and the VSS in studying and learning vocabulary prior to the treatment. Moreover, all of them were skillful in using computers before carrying out the treatment. They all assured to the researcher that they prefer using technology in language learning and in their daily activities.

The researcher pre tested the experimental group and the control group by using the pre VAT to be sure that they were both equivalent in their vocabulary in advance of conducting the treatment. Then, the researcher used the t-test to test the significance between them on the pre VAT. The result indicated that the mean score of the experimental group was 23.92 with a standard deviation of 3.40, while the mean score of the control group was 22.83 with a standard deviation of 2.96. This result showed that the difference in the mean scores between the experimental group and the control group on the pre VAT was not statistically significant $(t=1.54, p>0.05)$. It revealed that the two groups were equivalent in vocabulary prior to the treatment. Table 1 showed this result.

Table 1. The t-value of the difference in the mean scores between the experimental group and the control group on the pre VAT

\begin{tabular}{lllllll}
\hline Group & $\mathrm{N}$ & Mean & SD & DF & T & Sig. \\
\hline Experimental & 40 & 23.92 & 3.40 & \multirow{2}{*}{78} & \multirow{2}{*}{1.54} & 0.127 \\
\hline Control & 40 & 22.83 & 2.96 & & & \\
\hline
\end{tabular}

\subsection{Instrument}

\subsubsection{The VAT (See the Appendix)}

The researcher designed the VAT (See the Appendix) to be used as an instrument for assessing the participants' vocabulary before carrying out the treatment and after it. It was a 45 item multiple choice test of vocabulary with 4 options for each item. One mark was allocated for each correct answer which a participant gave. The researcher wrote the sentences of the VAT as she selected the vocabulary test items of the VAT from the lexical items found in units (1) to (40) provided in the student's textbook English Vocabulary in Use: Pre-intermediate \& Intermediate by Stuart Redman (1997) that was prescribed for first level students to study. The researcher wrote the VAT and its instructions in English. The instructions attached to the VAT were intended to provide the participants with information on how to answer the VAT.

The researcher piloted the VAT by submitting it to a sample of 21 first level students who were not included in the participants of the current study to reveal if this test and its instructions were clear, readable and understandable to first level students. The pilot sample indicated that the VAT and its instructions were perfect and understandable to them. The researcher also validated the VAT by submitting it to a jury of 7 professors of Curriculum and Teaching English as a Foreign Language (TEFL) instruction at some faculties of education and arts in KSA. All of the jury members agreed upon the validity of the VAT for assessing first level students' 
vocabulary because its items and instructions were understandable and suitable for their linguistic level and prior knowledge.

Timing of the VAT was determined by the same piloting and the researcher found that 40 minutes would be the suitable time for the participants to answer the VAT. The researcher used the Kuder-Richardson formula 20 (KR-20) to calculate the internal consistency reliability of the VAT. She found that it was at 0.83 which revealed that the VAT enjoyed an acceptable reliability co-efficient at 0.01 level. Moreover, the researcher used the test / retest method of calculating the reliability co-efficient of the VAT as she administrated it twice with a 15 day time span between the first and the second application on a random sample of 21 first level students who were not involved in the participants of the current study. The researcher found that the statistical co-efficient of Pearson on the VAT was at 0.89 that was a high co-efficient reliability at 0.01 level. This highlighted that the VAT proved to have a high degree of reliability.

\subsection{Materials}

\subsubsection{Selected Reading Materials for Teaching Vocabulary}

The researcher selected 5 reading texts from the Internet to be used for carrying out the training sessions of the VSSPlus with the experimental group. They were also intended to be used for teaching vocabulary to the control group by using the VSS. These reading texts included general vocabulary which might be useful for the participants to study because they were related to topics that might be encountered in their vocabulary textbook. The researcher submitted these reading texts to the same jury members to validate them. The jury members indicated that these reading texts were of reasonable and similar length and were of interest for the participants. They also revealed that these reading texts were proper for the linguistic level of the participants because they were appropriate in difficulty level regarding their vocabulary and grammar. They assured that these reading texts included unknown vocabulary which might need studying on the part of the participants to comprehend their meaning. Therefore, they agreed on the validity of all the reading texts for the current study.

\subsubsection{Training Sessions of Conducting the VSSPlus}

To design the training sessions of carrying out the VSSPlus, the researcher adopted the steps provided by Grisham et al. (2013) on using the VSSPlus for vocabulary teaching and learning. The researcher made some modifications for these steps to be more applicable for the experimental group of the current study. The purpose of the training sessions in the current study was to use them in training the experimental group on the use of the VSSPlus to develop vocabulary. The researcher submitted the training sessions to the same jury members in order to validate them. The jury members assured that the technological tools, the activities and the tasks given in the training sessions were applicable and suitable for the experimental group. Hence, they agreed upon the validity of these training sessions for the current study.

\subsection{Procedures}

The current study was carried out at Languages and Translation Department, Arar Faculty of Education and Arts, NBU, KSA because the researcher worked there. She taught Vocabulary Building course to first level students and noticed that they had weaknesses in English vocabulary. In fact, the academic standards of the National Commission for Academic Accreditation and Assessment (NCAAA) for faculties of education and arts in KSA indicated the importance of developing vocabulary among students at these faculties. The academic standards of the NCAAA also revealed the usefulness of using technological tools in teaching and learning of a FL. Hence, all universities in KSA supplied all of their facilities with various technological tools to be applied in teaching and learning. It was the case with NBU as its faculties were supplied with modern technological labs and it encouraged all of its students and instructors to make use of them in learning different subjects.

The treatment took 11 weeks with 7 hours per week as needed for training the experimental group on the use of the VSSPlus to improve vocabulary learning. The researcher used the VAT to pre test the experimental group and the control group for equivalence in vocabulary prior to carrying out the treatment. The researcher taught the two groups as she trained the experimental group by using the VSSPlus whereas she taught the control group by using the VSS for studying the same vocabulary of the same texts and during the same period of time as the experimental group. By the end of the treatment, the researcher used the post VAT to assess vocabulary among the control group and the experimental group. Then, she used the t-test to calculate the differences between the mean scores of the pre and post VAT. The treatment with the experimental group included the following sessions: The VSSPlus introductory session, the VSSPlus application to making an e-Dictionary session, the VSSPlus application to making a Wordsift session and the VSSPlus application to making a Thinglink session. The researcher helped the participants assign themselves into small teams of 4 students in each team. The researcher 
also allowed each team to distribute and exchange roles among themselves according to their desires in order to co-operatively do the activities required from them. The following section includes a description of the VSSPlus sessions.

\subsubsection{The VSSPlus Introductory Session}

The researcher first introduced to the experimental group the definitions of the VSS and the VSSPlus and the difference between them. She also illustrated the importance and purpose of applying the VSSPlus to vocabulary teaching and learning. She explained that this session was intended to help them be acquainted with the first step of conducting the VSSPlus concerning the procedures of selecting words from a post-reading text and the steps of answering questions on a selected word. Then, she used an oral PowerPointPresentation (PPT) to introduce a demonstration of the steps of selecting a word from a post reading text. She explained that they should ask themselves 3 questions when they select a word from a text. She asserted that the 3 questions are as follows: Where is the selected word found in the text?, what do you think the selected word mean?, and why do you think it is important to learn the selected word?. She clarified that answers to the questions involve defining the word, explaining why they should learn it and telling where the word was found.

The researcher modeled this step by selecting and presenting an important word which they had never studied, learnt or memorized before and which was found in a reading text that she had previously read aloud to them. Moreover, the researcher orally asked and gave answers to the 3 questions on the selected word. Then, she asked each small team to co-operate together to select from the previously post-reading text another word which is unknown in meaning to them and to ask and answer the same 3 questions on their own selected word. She encouraged each team to use a PPT to present their own selected word and answers to the 3 questions to other small teams and to discuss this demonstration with them to give additional clarifications for their selected word.

\subsubsection{The VSSPlus Application to Making an e-Dictionary Session}

The researcher asked the participants of each small team to individually and silently read the text which she had selected for them because she had found that this text might be of importance and interest to them and as it included unknown vocabulary to them. Then, the researcher encouraged each team to work together to select from the text one word which they would like to learn more about because they had never studied before. The researcher facilitated the process of word selection done by each team as she assisted each team to select an unknown word in meaning but considered important for comprehending the text. Then, each team was allowed to ask themselves the 3 questions on their selected word and to provide one answer to each question. The researcher asked the leader in each team to introduce a PPT to other small teams on the answers of own team to the 3 questions. She also gave each team the opportunity to discuss with other teams their selected word and their answers to the 3 questions. She encouraged the small teams of the experimental group to write all of the selected words in their notebooks because they might use these written words in other activities.

The researcher explained to the experimental group the importance of having an e-Dictionary as a means for helping them develop vocabulary. She showed some examples of e-Dictionary pages and discussed with them the parts that an e-Dictionary page should include. Then, she used a Wiki to make an example of an e-Dictionary page and she explained it by using a PPT to help them know how to make an e-Dictionary page and how to organize its parts. Moreover, the researcher trained the experimental group on how to make own audio-recording of a selected word and how to post it to an e-Dictionary page. She asked each team to work together to make their own e-Dictionary page and to use the Wikispaces to make the e-Dictionary first page. She facilitated co-operation among each team by providing instructions to complete making their e-Dictionary page. She also trained them on making additional pages on the Wikispaces to expand their learning of new words. Then, she asked each team to use the Internet to find definitions and images for their selected word and she helped each team agree on the definitions and images which represented their expectation of the meaning of the selected word. Each team was encouraged to view e-Dictionary pages of other teams to learn new vocabulary from these pages. She gave each team an opportunity to make own audio-recording of their own selected word and to post it to their own e-Dictionary page. Then, she discussed with the experimental group the importance of having an audio narration on a PowerPoint slide. She trained them on how to attach their previously made audio-recording of their own selected word to a PowerPoint slide to be presented to other teams to share it with them. She gave each team time to attach own audio-recording to a PowerPoint slide and to present it to other teams in order to share it with them.

\subsubsection{The VSSPlus Application to Making a Wordsift Session}

The researcher first clarified to the experimental group the definition of a Wordsift and purpose and advantages of using a Wordsift for helping develop vocabulary. She showed them an example of a Wordsift posted on a 
computer and explained its different parts. She trained them on the steps of using a Wordsift in typing a selected word and in producing a visual that links synonyms and related words to this word. Then, she asked each team to co-operate together in order to use a Wordsift in typing their own selected word and in making a visual which links synonyms and related words to their selected word which they had typed on the Wordsift. Each team was given a chance to introduce, and discuss with other teams their selected word which they had typed on their Wordsift and the visuals which had linked synonyms and related words to their selected word. Then, the researcher discussed with each team the additional synonyms of their selected word in order to help them use their selected word and its synonyms to form sentences. Moreover, she asked each team to write down their own selected word, its synonyms and related words in their notebooks. She also asked each team to write the selected word in correct sentences and to write the sentences in their notebooks. She checked the sentences written by each team and provided teams with suggestions for improvement.

\subsubsection{The VSSPlus Application to Making a Thinglink Session}

The researcher first explained to the experimental group the definition of a Thinglink, purpose and advantages of using a Thinglink for vocabulary teaching and learning. She showed them an example of a Thinglink and described its parts to comprehend it. Moreover, she trained them on locating a suitable image for a selected word and trained them on the use of editing tools provided on a Thinglink to tag the image with a text to give definitions and rationale for the selected word. She asked each team to write their team name on their own Thinglink to distinguish it from the Thinglinks of other teams. She gave each team the opportunity to use own Thinglink to study their own selected word and to comprehend its meaning. The researcher facilitated the teams' application of Thinglink by offering help when needed. Then, the researcher trained the experimental group on uploading the audio narration of a selected word to a podbean and on attaching the podbean to the Thinglink. Each team was given the chance to upload their own audio narration to their podbean and attach it to own Thinglink. Moreover, the researcher asked each team to write their selected word and its definitions and rationale in their notebooks to use them in doing other activities.

\section{Results}

\subsection{Hypothesis One Result}

The researcher used the t-test in order to check the difference in the mean scores between the experimental group and the control group on the post VAT. The result showed that the mean score of the experimental group on the post VAT was 37.92 with a standard deviation of 2.38, whereas the mean score of the control group on the post VAT was 23.53 with a standard deviation of 2.64 This result indicated that the difference in the mean scores between the experimental group and the control group on the post VAT was statistically significant $(t=25.62, p$ $<0.05$ ). Thus, the first hypothesis was accepted. Table 2 showed this result. The researcher used Brown's (2008) formula to estimate the effect size for the difference. The effect size was 0.894 which is considered large.

Table 2. The t-value of the difference in the mean scores between the experimental group and the control group on the post VAT

\begin{tabular}{lllllll}
\hline Group & $\mathrm{N}$ & Mean & SD & DF & T & Sig. \\
\hline Experimental & 40 & 37.92 & 2.38 & \multirow{2}{*}{78} & 25.62 & 0.000 \\
\hline Control & 40 & 23.53 & 2.64 & & & \\
\hline
\end{tabular}

\subsection{Hypothesis Two Result}

The researcher used the t-test to investigate the difference in the mean scores of the experimental group between the pre and post VAT. The result showed that the mean score of the experimental group on the pre VAT was 23.92 with a standard deviation of 3.40, while its mean score on the post VAT was 37.92 with a standard deviation of 2.38. This result showed that the difference in the mean scores of the experimental group between the pre and post VAT was statistically significant $(\mathrm{t}=20.03, \mathrm{p}<0.05)$. Therefore, the second hypothesis was accepted. Table 3 presented this result. The effect size for the difference was estimated by using Brown's (2008) formula and the researcher found that it was 0.911 and it is considered large. 
Table 3. The t-value of the difference in the mean scores of the experimental group between the pre and post VAT

\begin{tabular}{lllllll}
\hline Group & $\mathrm{N}$ & Mean & SD & DF & T & Sig. \\
\hline Pre Experimental & 40 & 23.92 & 3.40 & \multirow{2}{*}{39} & 20.03 & 0.000 \\
\cline { 1 - 5 } Post Experimental & 40 & 37.92 & 2.38 & & & \\
\hline
\end{tabular}

\section{Discussion}

The results in the current study indicated that a statistically significant difference was found in the mean scores between the experimental group and the control group on the post VAT in favor of the experimental group. The results also showed that there was a statistically significant difference in the mean scores of the experimental group between the pre and the post VAT in favor of the post VAT. Such results revealed that the experimental group outperformed the control group on the post VAT because of their use of the VSSPlus in vocabulary learning. The results also indicated that the experimental group developed vocabulary on the post VAT and performed better than they did on the pre VAT as a consequence of being exposed to the training sessions which based on the use of the VSSPlus in vocabulary learning. They also revealed that the VSSPlus proved to be an appropriate and effective strategy used for vocabulary development. The findings of the current study are consistent with the article written by Grisham et al. (2013) that the VSSPlus could be used as an effective strategy for developing vocabulary mastery among its users because it could encourage them to collaborate in their small teams in order to study their selected words to know their synonyms and meanings. The current study's results are also in agreement with Wolsey et al.'s (2015) article regarding that using technological tools in the VSSPlus could help its users enhance their interest in vocabulary acquisition and therefore this might lead to improve their vocabulary.

The VSSPlus provided the experimental group in the current study with a collaborative learning environment as they worked in teams of 4 students during the sessions of applying the VSSPlus in the current study. This is because it is known that when students co-operate together in a learning context, they perform well and learn better (Grisham \& Wolsey, 2014). Each team in the experimental group was encouraged to present their selected words and their meanings by using PPTs to other teams to share knowledge and exchange information related to the selected words introduced in their presentations. Each team was also given the opportunity to attach own PPTs, audio narrations and bodbean to their class wiki to be presented to other teams to share and discuss knowledge on their own selected words together and with other teams to benefit from them. Moreover, the VSSPlus helped the experimental group raise an awareness of the usefulness of learning content-area words. Therefore, they became able to correctly say and write new vocabulary and give its correct meanings.

The VSSPlus is characterized by implementing explicit instruction and intensive practice of the procedures of learning vocabulary by using many technological tools such as audio narrations files, e-Dictionary pages, PPTs, a Wordsift, a Thinglink, a Podbean and a Wiki. The integration of these technological tools into the VSSPlus encouraged the experimental group to be involved in extracting the synonyms and definitions of the vocabulary which they had selected from a post reading material. It also helped them view their own and other teams' vocabulary, synonyms, and definitions to deepen their knowledge about them to learn their meanings and to use them meaningfully in correct sentences. Moreover, the VSSPlus satisfied the requirements of making use of technological tools in the digital era. The experimental group became capable of practicing and recalling vocabulary when needed and hence the VSSPlus developed vocabulary among them.

The experimental group in the current study asserted that they enjoyed using the VSSPlus in studying new vocabulary. They emphasized that they became motivated to study and learn more new vocabulary as a result of the training sessions which they had received on using the VSSPlus in learning new vocabulary. They showed positive attitudes towards vocabulary learning by using the VSSPlus and assured that they would like to use the VSSPlus in the future with vocabulary learning. They indicated that they became more enthusiastic, interested and motivated to integrate technology in vocabulary learning to discover and understand the meaning of unknown vocabulary and to use new vocabulary to form correct sentences. Therefore, the VSSPlus proved to be effective in developing vocabulary among the experimental group especially on the aspect of selecting correct vocabulary in sentences.

\section{Conclusion}

It can be concluded from the findings of the current study that the use of the VSSPlus in vocabulary teaching and 
learning developed vocabulary among first level students. Hence, the VSSPlus is needed to be implemented by university EFL instructors who teach Vocabulary Building course to develop vocabulary learning among their students. The VSSPlus is also recommended to be individually and collaboratively used by university EFL students in order to help them develop learning of vocabulary.

\section{Recommendations}

The following recommendations can emerge from the results of the current study:

- More care should be directed to the use of the VSSPlus in vocabulary learning with university EFL students to help them develop vocabulary.

- University EFL instructors have to be exposed to training programs based on using the VSSPlus in vocabulary instruction to help their students develop vocabulary.

- Published handouts on the usefulness of implementing the VSSPlus in vocabulary teaching and learning should be available to university EFL instructors and students.

- Textbook writers have to include procedures of using the VSSPlus in the Vocabulary Building course given to first level students.

- University EFL students should be provided with training sessions which are based on training them on using the VSSPlus in vocabulary learning to help them develop vocabulary.

\section{Suggestions for Further Research}

The researcher suggests carrying out the following studies:

- Replicating the current study with a larger number of students for more generalization of the results.

- Investigating the impact of using the VSSPlus on developing vocabulary retention among university EFL students.

- Studying the effect of using the VSSPlus on university EFL students' motivation towards vocabulary learning.

- Examining the effectiveness of using other technological tools which were not used in the current study in developing vocabulary among university EFL students.

\section{References}

Albousaif. M. (2012). Factors determining Saudi learners' difficulties in attaining EFL vocabularv. (A Ph. D. Thesis). Universitv of Newcastle. Retrieved from http://ogma.newcastle.edu.au:8080/vital/access/manager/Repository/uon:10838

Al-Nuiaidi. A. (2003). The relationshin between vocabularv size. reading strategies. and reading comprehension of EFL learners in Saudi Arabia. (A Ph. D. Thesis). Oklahoma State Universitv. Retrieved from https://shareok.org/bitstream/handle/11244/44607/Thesis-2003D-A452r.pdf?sequence=1\&isAllowed=y

Altalhab. S. (2016). Teaching and learning vocabularv through reading as a social practice in Saudi universities. English Language Teaching, 9(11), 67-79. https://doi.org/10.5539/elt.v9n11p67

Arenseth. H. (2008). Activitv theorv and situated learning theorv: Contrasting views of educational practice. Pedagogy, Culture \& Society, 16(3), 289-302. https://doi.org/10.1080/14681360802346663

Brown, J. (2008). Effect size and eta squared. JALT Testing \& Evaluation SIG Newsletter, 12(2), 38-43.

Celik. S. \& Tontas. V. (2010). Vocabularv learning strategies of Turkish EFL learners. Procedia-Social and Behavioral Sciences, 3, 62-71. https://doi.org/10.1016/j.sbspro.2010.07.013

Chen. J. (2014). On vocabularv presentation modes in college English teaching and learning. Theorv and Practice in Language Studies, 4(4), 818-823. https://doi.org/10.4304/tpls.4.4.818-823

Clark. M. (2013). The use of technologv to sunbort vocabularv develonment of English Language learners. (Master's thesis). Retrieved from http://fisherpub.sjfc.edu/education_ETD_masters/238

Dalton, B., \& Grisham, D. L. (2011). E-Voc strategies: 10 ways to improve vocabulary teaching using technology. The Reading Teacher, 64(5), 306-317. https://doi.org/10.1598/RT.64.5.1

Dolati, I., \& Mikaili, P. (2011). Opinion related to the main reasons on Iranian students difficulties in spoken English proficiency. Australian Journal of Basic and Applied Science. Retrieved from http://www.ajbasweb.com

Eckerth, J., \& Tavakoli, P. (2012). The effects of word exposure frequency and elaboration of word processing on incidental L2 vocabulary acquisition through reading. Language Teaching Research, 16(2), 227-252. 
https://doi.org/10.1177/1362168811431377

Gersten, R., \& Baker, S. (2000). What we know about effective instructional practices for English language learners. Exceptional Children, 66(4), 454-470. https://doi.org/10.1177/001440290006600402

Ghazal, L. (2007). Learning vocabulary in EFL context through vocabulary learning strategies. Novitas-ROYAL, $1,84-91$.

Godwin Jones, R. (2010). Emerging technologies, from memory places to spacing algorithms: Approaches to second language vocabulary learning. Language Learning \& Technology, 14, 4-11.

Grisham. D. L.. \& Smetana. L. (2011). Generative technologv for teacher educators. Journal of Reading Education. 36(3), 12-18.

Grisham, D. L., \& Wolsey, T. D. (2014). Podcasting for deeper science learning. California Reader, 47(3), 18-26.

Grisham. D. L.. Wolsev. T. D.. \& Smetana. L. (2013).Vocabularv Self-Collection Strategv Plus (VSS+). Retrieved from https://literacybeat.com/2013/10/23/vocabulary-self-selection-strategy-plus-vss/

Haggard. M. (1982). The vocabularv self-collection strategv: An active abbroach to word learning. Journal of Reading, 26(3), 203-207.

Haggard. M. (1986). The vocabularv self-collection strategv: Using student interest and world knowledge to enhance vocabulary growth. Journal of Reading, 29(7), 634-642.

Hoshino, Y. (2010). The categorical facilitation of L2 vocabulary learning in a classroom setting. RELC Journal, 41(3), 301-312. https://doi.org/10.1177/0033688210380558

Hulstiin. J. (2001). Intentional and incidental second language learning: A reanbraisal of elaboration. rehearsal and automaticitv. In P. Robinson (Ed.). Connition and second language acauisition instruction ( $\mathrm{nn}$. 258-286). Cambridge: Cambridge University Press. https://doi.org/10.1111/0023-8333.00164

Kabiri, R., \& Ghafoori, N. (2014). The impact of playing word games on young Iranian EFL learners' vocabulary learning and retention. The Journal of Applied Linguistics, 7(14), 68-82.

Kilickaya, F., \& Krajka, J. (2010). Teachers' technology use in vocabulary teaching. Academic Exchange Quarterly, 14, 81-86.

Lester. J.. \& Elliott. M. (2002). Literacv and learning: Reading in the content areas: Handbook IV for teachers in grades 5-8. Southeastern Louisiana University: Louisiana Public Broadcasting.

Perez, M., Peters, E., Clarebout, G., \& Desmet, P. (2014). Effects of captioning on video comprehension and incidental vocabulary learning. Language Laerning \& Technology, 18(1), 118-141.

Scott, W., \& Ytreberg, L. (2001). Teaching English to children. New York, Longman.

Stoddard. T. (2006). Vocabularv Self-Collection Strategv with an example from Ender's Game bv Orson Scott Card. $\quad$ Retrieved from http://www.google.co.id/url?q=http://novelinks.org/uploads/Novels/EnderGames/vocabularyself.pdf

Wilkins, D. (1972). Linguistics in language teaching. Australia: Edward Arnold.

Willis, D., \& Willis, J. (2007). Doing task-based teaching. Oxford: Oxford University Press.

Wolsev. T. D.. Grisham. D. L. \& Smetana. L. (2014). Using technologv in the unner elementarv grades to sunnort writing with digital media and sources (Grades $4-6$ ). In K. Ganske (Ed.). Write now! Embowering writing in today's $K-6$ classrooms. Newark, DE: International Reading Association.

Wolsev. T. D.. Smetana. L.. \& Grisham. D. L. (2015). Vocabularv plus technologv: An after-reading approach to develop deep word learning. Reading Teacher, 68(6), 449-458. https://doi.org/10.1002/trtr.1331

Wulansari. L. (2016). The use of Vocabularv Self-Collection Strategv (VSS) to improve Students' vocabularv masterv at second grade students of SMP IT Tunas Harapan Plupuh Sragen. Retrieved from http://jurnal-mahasiswa.unisri.ac.id/index.php/fkiping/article/download/340/283

Yule, G. (2006). The study of language. Cambridge: Cambridge University Press.

\section{Copyrights}

Copyright for this article is retained by the author(s), with first publication rights granted to the journal.

This is an open-access article distributed under the terms and conditions of the Creative Commons Attribution license (http://creativecommons.org/licenses/by/4.0/). 